\title{
Predatory ants: first report on direct evidence of predation by Dorylus orientalis Westwood, 1885 on olive ridley eggs from India.
}

\author{
Sumedha Korgaonkar ${ }^{1}$, Anuja Vartak ${ }^{2}$, K Sivakumar $^{1}$
}

1 Wildlife Institute of India, Department of endangered species management, Dehradun, Uttarakhand, India.

2 Annasaheb Kulkarni department of biodiversity, MES Abasaheb Garware College, Pune, Maharashtra, India.

Corresponding author email: Sumedha_19@wii.gov.in

\begin{abstract}
:
Predation of eggs and emerging hatchlings of olive ridley turtle (Lepidochelys olivacea) by wild animals and feral dogs are known. They reduce the hatching success rate considerably affecting the conservation management of this vulnerable species. Hatchery management is practiced in India to overcome predation. Ant predation is a serious threat to turtle nest protected by ex situ or in situ erected hatchery. This article reports the first direct evidence of turtle eggs predation by Dorylus orientalis Westwood, 1835 commonly called red ants. Native to India, Oriental, Indo Australian and Palearctic regions they are notorious as an agricultural pest. Chlorpyrifos pesticides recommended for their control could become fatal for the developing embryos of turtles if applied near the hatchery. In the turtle nesting site of the west coast of India, D. orientalis has more of an ecological role than as a pest. Natural pesticide such as Neem powder (Azadirachta indica) shows promising results for preventing their infestation.
\end{abstract}


Keywords: Red ants, Ex-situ, Conservation, Hatchery, Sea turtles, Lepidochelys olivacea.

\section{Highlights:}

- Ant predation of protected nest is a concern for conservation management of sea turtles.

- $0 \%$ emergence is mostly observed in ant predation.

- The first direct evidence of D. orientalis predation on sea turtle eggs.

- There is lack of knowledge about D. orientalis ecological role and behavioural aspect.

- Study of the behavior of D. orientalis will help in effective conservation management.

\section{Introduction:}

Olive ridley turtles (Lepidochelys olivacea Eschscholtz, 1829) having a broad distribution in the tropical belt is the most populous among the seven species of sea turtles. They are classified as vulnerable under IUCN status and protected as Schedule I under the Indian Wildife Protection Act, 1972. This species shows two distinct nesting behaviour, a unique and rare mass nesting called 'Arribada' and solitary nesting (Dornfeld et al., 2015). India harbours both mass nesting at Rushikulya and Gahirmatha coast of Odisha and solitary nesting population in east and west coast of India. The solitary nesting female during nesting season from November to March come on sandy beaches to lay eggs. The eggs are laid inside the sand in pot shaped pit dug by the female with her hind flippers. On the Indian coasts, the clutch size varies from 75-135 and the incubation period lasts from 45 -60 days. Freshly laid eggs though covered by sand are vulnerable to natural predators. The wild predators such as jackals, birds, hyenas, crabs, and feral dogs are known to predate eggs in the fresh nest and on hatchlings during emergence (Tripathy \& Rajasekhar, 2009). 
In-situ and ex-situ protection of nest in the permanent or temporary erected hatchery is practised in India as conservation management. During nesting season egg predation by wild animals is prevented by patrolling the beach and relocating the eggs in a hatchery. Hatchling predation is prevented by releasing them near the high tide mark under supervision (Kurian, 2013). The hatchery management practised in India has considerably reduced the predation rate of wild animals and feral dogs. Inadequacy of hatcheries to control ant attack is evident with reports of hatchling predation.

Fire ants such as Solenopsis geminata and Solenopsis invicta is known for attacking emerging hatchlings from Florida and EL Salvador coast of America (Allen et al. 2001). It has been observed that the fire ants negatively impact the hatching and emergence success rate. The nest which were laid close to dune vegetation was seen attacked by Solenopsis spp. The ants were reported stinging piped and emerging hatchlings than developing embryos. The ant predation of sea turtle nest by various species has been recorded in other countries (Allen et al. 2001; Wetterer et al. 2007). A single incident of olive ridley (L. olivacea) nests destroyed by unidentified ant species from Maharashtra, west coast of India is reported (Kelaskar et al. 2016). The persistent problem of ants predating on ex-situ protected turtle nest was observed at one of the sea turtle rookery site in south coastal Maharashtra for past seven consecutive years. An average of 35\% $50 \%$ of the total nests was infested with ants and showed $0 \%-10 \%$ emergence (personal communication). In 2018 -19 nesting season out of nine, four nests were $100 \%$ destroyed by ants. 


\section{Study area:}

Wayangani- Vengurla beach $\left(15^{\circ} 52^{\prime} 19.50^{\prime \prime} \mathrm{N}, 7^{\circ} 36^{\prime} 28.72^{\prime \prime} \mathrm{E}\right)$ in Sindhudurg district of coastal Maharashtra, is one of the best rookery site for olive ridley turtle. Conservation management program is been conducted over a decade in this site for protection of sea turtles from human poaching.

\section{Materials and Methods:}

The ants present inside the nest and eggs were collected live for taxonomic identification. The collected specimens were later preserved in $80 \%$ ethanol in lab and refrigerated. The specimens were relaxed and spread before photographing by Magnus 7OT 0650 stereo zoom microscope. The post processing of images were done in GIMP 2.10.18 (Joshi et al. 2020). Identification of the ant species was done with key characters described by Bingham in Fauna of British India (1903) and Bolten (1990). The species identification was confirmed by H Bharati.

\section{Results and Discussion:}

\subsection{Taxanomic identification and morphological characters of ants.}

In this article, we report for the first time from India the direct evidence of Dorylus orientalis Westwood, 1835 commonly called as red ants predating on sea turtle nest. It belongs to subfamily Dorylinae of family Formicidae. The morphological characters of workers show antennae having nine segments, eyes absent, head rectangular, occiput deeply emarginated. Thorax elongate, constricted at pro-mesonotal suture, legs short, robust and single node of the pedicel (Fig. 1a, b). 


\subsection{Observation of D. orientalis predating on turtle eggs inside the nest.}

The ants were found active during the day inside the protected nest of olive ridley sea turtle on the sandy beach. Post the incubation period when the nest were opened it showed $0 \%$ hatching success (Fig. 2 a). The eggs shells having distinct holes had underdeveloped embryo with ants present inside them (Fig. 2 c, d). The ants in large number were seen escaping through the tunnel made $90^{0}$ to the base of the nest at a depth of 1.25 feet (Fig. 2 b).

\subsection{Reports on predatory behavior of D orientalis.}

Chan and Liew (1999) reported nest predation of Hawks billed turtle by red ants from Malaysia. The red ants were identified as three native species Dorylus orientalis Westwood, Lophomyrmex sp. and Pheidole sp (Wetterer et al. 2007). Mc Allister (1965) and Hughes (1971) have reported driver ants of Dorylus sp from Tongaland South Africa infesting Loggerhead (Caretta caretta) and Leatherback (Dermochelys coriacea) turtle nest. In the absence of any control measures the unprotected wild eggs were attacked at the last stages of development and resulted in $100 \%$ mortality. D. orientalis is native to Indo Australian, Oriental and Palearctic region and must differ from driver ant Dorylus sp from South Africa.

\subsection{Ecological role of D. orientalis.}

D. orientalis is a known agricultural pest native to India, Pakistan, Bhutan, Srilanka, Myanmar, Indonesia, Hong Kong, Vietnam, Malaysia (Riaz et al. 2019). In India, it is widely distributed and has been reported from most of the states as an agricultural pest (Bharti et al. 2016). This is a subterranean species with scarce information on life histories. It is known to destroy potato, cabbage, cauliflower, coconut seedling, groundnut, sugarcane crop from Northeast, Bihar, Uttar Pradesh, West Bengal and Kerala state reducing, the yield by 40- 90\% (Saikia and Nath 
2017). Most of these crops are cash crops in these agricultural states resulting in a focus on its pest management by using a chemical pesticide. The old world army ant belonging to subfamily Dorylinae consists of a single genus Dorylus which is further divided into six genera. Except one, all the five subgenera of Dorylus are subterranean. D orientalis belongs to subgenus Alaopone and is phylogenetically closely related to Dorylus (Alaopone). cf. vishnui and Dorylus (Dichthadia) laevigatus. Gotwald (1982) reported that the army ants can kill, dissect and feed on vertebrate prey due to their sharp cutting mandibles and large colony. Though D. orientalis was originally identified as an agricultural pest Mukerjee (1930) reported the mandibles of D. orientalis Westwood were structured to be carnivorous (Fig. 1c). D. orientalis is known as an agriculture pest, their close phylogenetic proximity with carnivorous species and direct evidence of them attacking early development eggs suggest their broad range of food preference. $D$. orientalis seems to feed on starchy as well as the fatty food. The species is reported from wide habitat from hills to plains but mostly agriculture land (Bharti et al. 2013). The samples of this species were collected from sandy beaches adding a new habitat preference to its existing habitat. Vayangani beach, the sample collection site is surrounded by coconut plantations on the northern side and Casuarina plantations on the southern part of the beach. Ipomea pes-caprae is the natural dune vegetation. Excluding mango orchard and coconut plantation no particular crops are cultivated in this region. The beach on its east side is surrounded by a hill with mango cultivation. This site is considered as an important rookery for ex-situ olive ridley turtle conservation in Maharashtra. An oral history of villagers suggests that the ants are historically present in this area. They can sometimes emerge in the houses having cow dung flooring and mud walls. These ants are seen in mango orchard scavenging on raw mangoes fallen on the ground. The damage to coconut and mango plantation from this site is unobserved. The role of $D$. orientalis in this site is suggestive of ecological than 
an agricultural pest. Bharti et al (2009) reported that $D$. orientalis forage between temperatures $24^{0} \mathrm{C}$ to $29^{\circ} \mathrm{C}$. The predatory activity on site was observed in March and April when the average ambient temperature is above $32^{\circ} \mathrm{C}$ suggesting their tolerance to high temperature. It was observed that the ants showing activity inside the nest when exposed to broad daylight vanished quickly into the sand probably due to low tolerance for bright light. There might be a possibility of a long tunnel under the sand leading towards their nest. Further investigation is required to study their hypogaeic style of living. The $D$. orientalis attack is considered to be critical for conservation management as their activity is inconspicuous on the surface. Their presence is felt only after $0 \%$ hatchlings fail to emerge from nest after completion of the incubation period. The phylogenetic analysis shows that D. (Alaopone) orientalis along with other two closely related species has a complete subterranean life dating back to 45.6 mya (Kronauer et al. 2007). The absence of eyes and short legs is characteristics of subterranean life. Their occasional presence on the ground in mango orchard and house may suggest a secondary adaptation to epigaeic foraging as that of closely related D. (Alaopone) $c f$ vishnui (Berghoff 2002).

\subsection{Management of D. orientalis in conservation of olive ridley turtles.}

Chemical pesticides such as Malathion, Dursben, Carbofuran, Servin and Chlorpyrifos are used as agriculture pest control against D. Orientalis (Dash et al. 2013; Saikia and Nath 2017). Most of these chemical pesticides are potent toxins for humans and are banned in many countries. Any form of chemical insecticide or formicide should be strictly avoided near the hatchery as it may leach out in the sand and into the nest affecting the development of turtle embryos. We suggest the use of Neem powder (Azadirachta indica) outside the protected hatchery that can be incorporated at the depth of 1.5 feet in layers (fig). This method was tested in 2019-2020 nesting season with positive results showing $0 \%$ infestation. All the protected nest were free from ant 
attack and showed $>50 \%$ hatchling emergence. Further studies regarding the ecology and subterranean foraging behaviour of $D$. orientalis needs to be explored. A low cost locally available natural insecticide which will prevent ant attack and not harm the developing embryos or the beach habitat need to be identified and their correct usage has to be evaluated.

\section{Acknowledgement}

The authors wish to thank The Mangrove and Marine Biodiversity Conservation Foundation of Maharashtra- small grants programme for funding this work. We thank Dr. Hemant Ghate for helping in taxonomic photography and Dr. Himender Bharti (Punjabi University and Member IUCN) for identification of the ant specimens. We wholeheartedly appreciate the efforts of Shri Suhas Toraskar from Vayangani Vengurla village in helping logistically for the execution of this project. We thank Dr Sameer Padhye for reviewing the script and suggesting changes. Lastly we thank officials of Maharashtra state forest department for granting permission to conduct the research work (Desk-22(8)/WL/CR-88 (16-17)/34/ 2019 -20). 


\section{References:}

Allen, C. R., Forys, E. A., Rice, K. G., \& Wojcik, D. P. (2001). Effects of fire ants (Hymenoptera: Formicidae) on hatching turtles and prevalence of fire ants on sea turtle nesting beaches in Florida. Florida Entomologist, 84(2), 250-253. https://doi.org/10.2307/3496175

Berghoff, S. M., J. Gadau, T. Winter, K. E. Linsenmair, and U. Maschwitz. (2003). Sociobiology of hypogaeic army ants: characterization of two sympatric Dorylus species on Borneo and their colony conflicts. Insectes sociaux, 50(2), 139-147.

Bharti H., Y. P. Sharma, and A. Kaur. (2009). Seasonal patterns of ants (Hymenoptera: Formicidae) in Punjab Shivalik. Halteres, 1(1), 36-47.

Bharti, H., Sharma, Y. P., Bharti, M., \& Pfeiffer, M. (2013). Ant species richness, endemicity and functional groups, along an elevational gradient in the himalayas. Asian Myrmecology, 5(1), 79-101.

Bharti, H., Guénard, B., Bharti, M., \& Economo, E. P. (2016). An updated checklist of the ants of India with their specific distributions in Indian states (Hymenoptera, Formicidae). ZooKeys, 551, 1-83. https://doi.org/10.3897/zookeys.551.6767

Chan, E. H., and H.C. Liew. (1999). Hawksbill turtles, Eretmochelys imbricata, nesting on Redang Island, Tereng- ganu, Malaysia, from 1993 to 1997. Chelon. Conserv. Biol, 3, 326-329.

Dash, C. K., K. Hassan, M.E.A. Pramanik, M. H. R. (2013). Development of Management Stratigies Against Red Ant (Dorylus Orientalis Westwood) of Potato. October. https://doi.org/10.13189/ujps.2013.010303

Dornfeld, T. C., Robinson, N. J., Tomillo, P. S., \& Paladino, F. V. (2015). Ecology of solitary nesting olive ridley sea turtles at Playa Grande, Costa Rica. Marine Biology, 162(1), 123-139. https://doi.org/10.1007/s00227-014-2583-7

Gotwald, W. (1982). Taxonomic Implications of Dorylinae Worker ant Morphology: Dorylus Subgenus Anomma (Hymenoptera: Formicidae). Sociobiology, 7 (2).

Hughes, G. R. (1971). The marine turtles of Tongaland. V. Lammergeyer, 13, 7-24. 
Joshi, N., Ghate, H., \& Padhye, S. (2020). Digital image post processing techniques for taxonomic publications with reference to insects. Journal of Threatened Taxa, 12(1), 15173-15180.

Kelaskar, A., M. Upadhye, S. Korgaonkar. (2018). Lesser known natural threats to protected olive ridley nests in coastal Maharashtra. Indian Ocean Turtle Newsletter, 24, 6-7.

Kronauer, D. J. C., Schöning, C., Vilhelmsen, L. B., \& Boomsma, J. J. (2007). A molecular phylogeny of Dorylus army ants provides evidence for multiple evolutionary transitions in foraging niche. BMC Evolutionary Biology, 7, 1-11. https://doi.org/10.1186/1471-2148-7-56 7

Kurian, A. (2013). Maine turtles along the Indian Coast: distribution, status, threats and management implications. WWF Report, 175.

McAllister, H. J., A. J. Bass, and H. J. Van Schoor. (1965). The marine turtles of Tongaland, Natal. Lammergeyer, 3, 10-40.

Mukerjee D. (1930). Report on a collection of ants in the Indian Museum, Calcutta. J. Bombay Nat. Hist. Soc, 34, 149-163.

Riaz, H., Bodlah, I., Qureshi, M. S., Rasheed, M. T., Ahmed, S., \& Hassan, M. A. (2019). Dorylus orientalis Westwood, 1835: New record for Pakistan (Hymenoptera: Formicidae) . Journal of Entomology and Zoology Studies, 7(4), 655-656.

Saikia, N., \& Nath, K. D. (2017). Efficacy of various pesticides against Red ant (Dorylus orientalis, Westwood) of potato. Journal of Applied and Natural Science, 9(4), 2350-2352. https://doi.org/10.31018/jans.v9i4.1536

Tripathy, B., \& Rajasekhar, P. S. (2009). Natural and anthropogenic threats to olive ridley sea turtles (Lepidochelys olivacea) at the rushikulya rookery of Orissa coast, India. Indian Journal of Marine Sciences, 38(4), 439-443.

Wetterer, J. K., Wood, L. D., Johnson, C., Krahe, H., \& Fitchett, S. (2007). Predaceous Ants, Beach Replenishment, and Nest Placement by Sea Turtles. Environmental Entomology, 36(5), 1084-1091. https://doi.org/10.1603/0046-225X(2007)36[1084:PABRAN]2.0.CO;2 